\title{
PARAGANGLIOMA OF URINARY BLADDER - A RARE CASE
}

Dr. Srujana Shyamala, Dr. S. S. S Quadri. Dr. N Sreemani Kumari, Dr. P Jijiya Bai, Dr. Jahagirdar.R

1. Assistant Professor, Department of Pathology, Gandhi Medical College, Secunderabad.

2. Assistant Professor, Department of Pathology, Gandhi Medical College, Secunderabad.

3. Associate Professor, Department of Pathology, Gandhi Medical College, Secunderabad.

4. Professor and Head, Department of Pathology, Gandhi Medical College, Secunderabad.

5. Associate Professor, Department of Urology, Gandhi Medical College, Secunderabad.

\section{CORRESPONDING AUTHOR}

Dr. Srujana Shyamala,

H.no - 11-3-378/2,

Srinivasnagar, Padmarao Nagar,

Secunderabad, Andra Pradesh,

E-mail: pvsrujana@gmail.com,

Ph: 91-9490312560.

ABSTRACT: A 27 year old male presented with hematuria \& dysuria since 9 months. Hematuria was transient at times, pain less \& terminal. History of passing clots occasionally. Ultrasound revealed echogenic isolated mass measuring $5 \times 4.6 \mathrm{~cm}$ arising from anterolateral wall of bladder with evidence of small foci of calcification at the periphery.

Partial cystectomy was done-but marked fluctuation in blood pressure and tachycardia was observed during the procedure. The histopathological findings were diagnostic of paraganglioma of the urinary bladder. The diagnosis was confirmed by means of immuno histochemical studies.

KEY WORDS: Paraganglioma, extraadrenal pheochromocytoma, bladder neoplasms.

INTRODUCTION: Paragangliomas originating in urinary bladder are extremely rare, arising from chromaffin tissue of the sympathetic nervous system. It is usually benign. The tumor usually develops in young adult women. Common symptoms and signs are dysuria, hematuria, and hypertension. We report a single case of non-functional paraganglioma of the urinary bladder clinically diagnosed as transitional cell carcinoma.

CASE REPORT: A 27 years old male presented to outpatient clinic of urology department with a 9 month history of hematuria and dysuria. He had no significant past medical history. His family history was non contributory. Physical examination was unremarkable, no organomegaly was observed. At admission, his blood pressure was 120/80 mm of $\mathrm{Hg}$, pulse rate was normal. Both ultrasound and CECT demonstrated isolated, enhancing sessile mass measuring $5 \times 4.6 \mathrm{~cm}$ arising from right anterolateral wall of urinary bladder with specks of calcification. Perivesical fat planes were preserved. Wall thickness appeared normal.

No calculi or evidence of any metastatic disease was observed.

Routine blood tests like CBP, LFT RFT were within normal limits. Urine examination showed pus cells 50-55/ hpf, Epithelial cells-10-12/ hpf, RBC 12-15/ hpf, Albumin 3+ (strip / manual method).

On the basis of the clinical diagnosis of primary bladder tumor, patient was admitted for partial cystectomy. During surgery, marked fluctuation in blood pressure with rise of blood pressure upto 230/80 mm of $\mathrm{Hg}$ and pulse rate of 200/minute was observed. Patient developed intraoperative cardiac arrest and was revived after DC shocks and was kept on ionotropic 
infusion and mechanical ventilator. He attained conscious state on $2^{\text {nd }}$ day of surgery. On follow up, his blood pressure and pulse rate are within normal limits.

MACROSCOPIC AND MICROSCOPIC FINDINGS: Grossly specimen received consisted of two soft tissue masses showing brown to yellow color. Largest mass measured $5 \times 2.5 \times 1 \mathrm{~cm}$ and smaller mass $3 \times 2 \times 1 \mathrm{~cm}$. On cut section, the both masses displayed uniform/homogenous yellowish brown appearance with no evidence of hemorrhage or necrosis.

Histopathological examination revealed a neoplasm composed of tumor cells arranged in nesting pattern and zell ballen pattern with delicate fibrovascular stroma. Individual cells are large round to polygonal with distinct cell border, abundant eosinophilic granular cytoplasm and vesicular nucleus. Mitoses are absent. A provisional histopathological diagnosis of paraganglioma of urinary bladder was made.

On immunohistochemistry, this bladder tumor was negative for epithelial marker cytokeratin and positive for the neuroendocrine markers - chromogranin, synaptophysin. Sustentacular cells showed positivity for S-100, thereby confirming the diagnosis of Paraganglioma of urinary bladder.

DISCUSSION: Paragangliomas are extra adrenal neoplasms arising from chromaffin tissue of the sympathetic nervous system. According to the latest edition Campbell Walsh Urology ${ }^{1}$, trigone and posterior wall of urinary bladder have been stated as the most common sites for paraganglioma, while in our case,the tumor arised from the antero lateral wall. The first case of paraganglioma of the urinary bladder was reported by Zimmerman ${ }^{2}$ in 1953 . Paraganglioma of the urinary bladder accounts for $<1 \%$ of all bladder tumors and $0.6 \%$ of extra adrenal pheohromocytomas ${ }^{3}$. In most cases, paragangliomas of the urinary bladder often causes micturitional attacks, headache, palpitation, fainting and visual disturbances. No such symptomatology was seen in our case. During surgery, marked fluctuation in blood pressure with tachycardia was observed 4 .

The tumor usually show females preponderance in ( $F$ : $M=3: 1$ ), occurring in 20-40 years of age, while this case was 27 years old male.

In most series patients may present with headache, palpitation, paroxymal HTN due to catecholamine excess especially during micturition. As the patient in our study had none of these symptoms, hence no endocrine tests were performed 5. As many as $50 \%$ of the paragangliomas are hereditary and may be associated with familial paragangliomas, neurofibromatosis type1,Von Hippel Lindau disease and the Carney triad 6 .

Macroscopically, these tumors are red-brown lobulated solid, submucosal or intramural masses covered by intact epithelium. They are as large as $10 \mathrm{~cm}$ but most are only a few centimeters in greatest dimensions. They usually appear as fungiform rounded or pedunculated masses that bulge into the lumen with variable ulceration.

On microscopic examination: tumor shows nests of cells arranged in zellballen pattern or trabecular architecture or a mixture of the two, diffuse or solid architecture can also be seen? Individually, tumor cells are large with abundant granular and basophilic to amphophilic cytoplasm with cellular and nuclear pleomorphism. Sometimes prominent nuclear pseudoinclusions are present in some cases. Spindle cells are present in about $2 \%$ of cases.

A small cell variant is also described. Intracytoplasmic hyaline globules occur commonly. These are PAS positive and diastase resistant. Hemorrhage and hemosiderin deposits are common.Oncocytic variants have also been reported. 
IHC paragagliomas are positive for chromogranin-A, synaptophysis and NSE. S-100 protein demonstrates sustentaular cells.

CONCLUSION: Bladder paragangliomas may be misdiagnosed when characteristic symptoms are absent. Although it shows female preponderance, our case is a 27 year male.

It should be considered as a differential diagnosis in neoplasm of urinary bladder. Laparoscopic partial cystectomy may be the first choice in treating paraganglioma of the urinary bladder. Recurrence and metastasis though infrequent, have been reported in the literature; therefore, long term follow up is required.

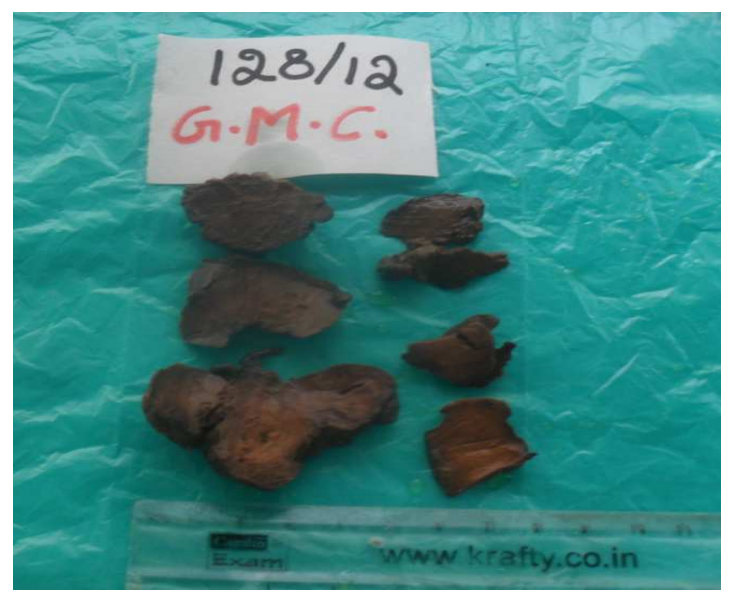

GROSS: Both masses displayed uniform/homogenous yellowish brown appearance with no hemorrhage or necrosis. Largest measuring $5 \times 2.5 \times 1 \mathrm{~cm}$ and smaller $3 \times 2 \times 1 \mathrm{~cm}$.
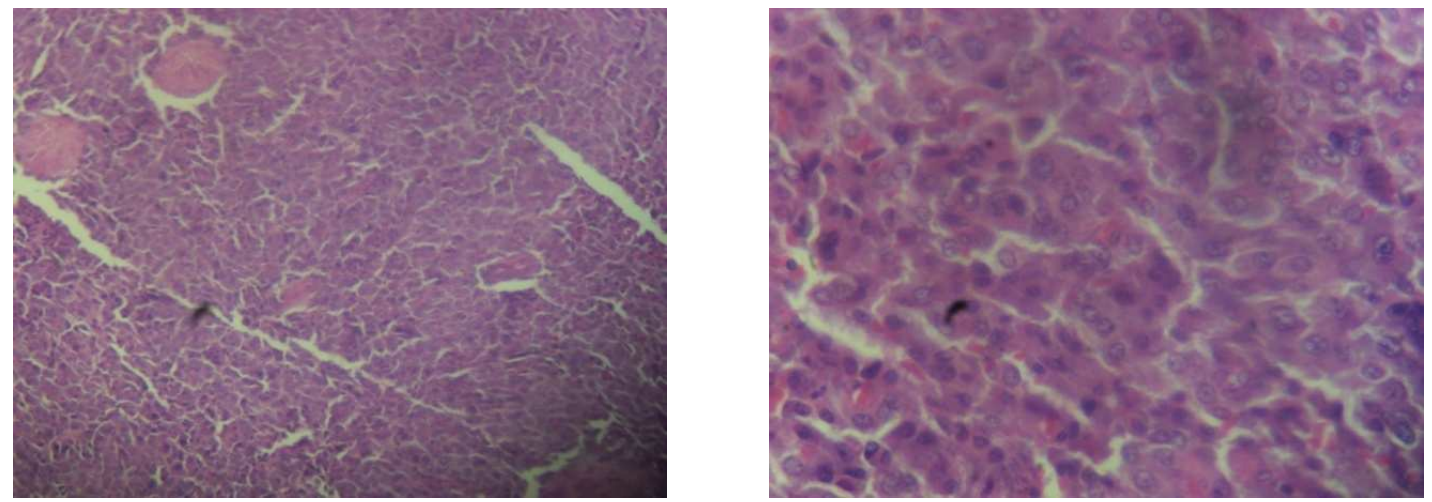

HPE: LP (10x) view: neoplasm composed of tumor cells arranged in nesting and zell ballen pattern with delicate fibrovascular stroma. HP view (40x): Individual cells are large round to polygonal with distinct cell border, abundant eosinophilic granular cytoplasm and vesicular nucleus. Mitoses are absent 


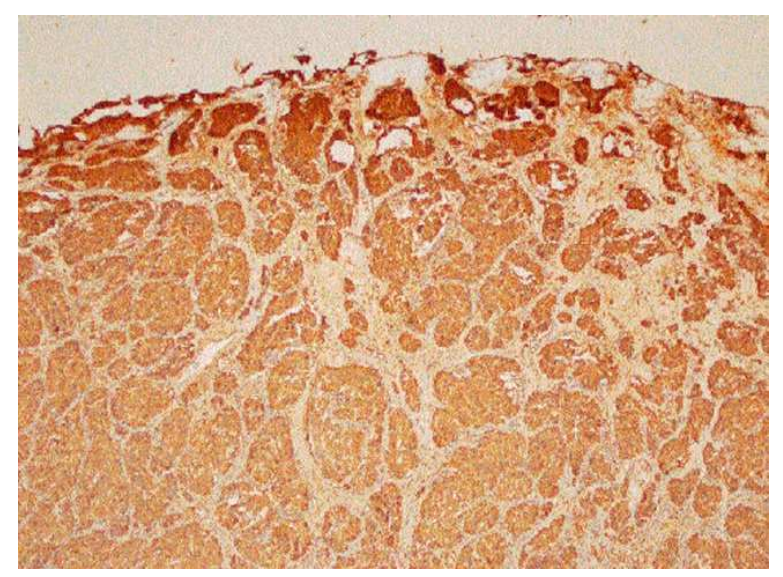

I H C: Tumor showing positivity for neuroendocrine markers - Chromogranin A

\section{REFERENCES:}

1. Messing EM.Urothelial tumors of bladder. In : Wein AJ, Kavoussi LR, Novick AC, Partin AW, Peters CA,editors Campbell Walsh Urology, $9^{\text {th }}$ edPhiladelphia:Saunders;2007.p.2407

2. Zimmerman IJ, BironRE, Macmohan HE: Phaeochromocytoma of the urinary bladder.

1. N Engl J Med 1953, 249(1):25 -26.

2. 3.Yadav R,Das AK,Kumar R.Malignant non functional paraganglioma of bladder presenting with azotemia.Int Urol Nrphrol,2007;39: 449- 51.

3. Ikeda M, EndoF,Shiga Y, Oguchi T, Yashi M, Hattori K, Maraishi O:Cystoscopic assisted partial cystectomy for paraganglioma of the urinary bladder.Hinoyokika Kiyo 2008,54(9):611-614.

4. 5.Thrasher JB, Rajan RR,Perez LM, Humphrey PA, Anderson EE:Pheochromocytoma of urinary bladder:contemporary methods of diagnosis and treatment options.Urology 1993,41(5):435-439.

5. Young WF Jr.Paragangliomas:clinical overviewAnn N Y Acad Sci.2006;1073:219.

6. Zhou M,Epstein JI,Young RH: Paraganglioma of urinary bladder: a lesion that may be misdiagnosed as urothelial carcinoma in transurethral resection specimens. Am J Surg Pathol 2004, 28(1):94- 100. 